\title{
Tarefa de leitura de palavras em voz alta: uma proposta de análise dos erros
}

\author{
Ângela Maria V. Pinheiro \& Carolina Rezende da Cunha \\ Universidade Federal de Minas Gerais, Brasil
}

Patrícia Silva Lúcio

Faculdade de Minas, Brasil

\begin{abstract}
Resumo
O presente estudo investiga as estratégias utilizadas por crianças brasileiras na leitura em voz alta de palavras isoladas. Tomando como foco a investigação da natureza dos erros que geraram palavras reais, distinguiramse os tipos de respostas que sugeriam a utilização do processo lexical reconhecimento automático de palavras - daquelas que sugeriam o uso do processo fonológico - a construção da pronúncia e do significado da palavra a partir da aplicação de regras de conversão grafema-fonema. Concluiu-se que as "respostas palavras reais", no português brasileiro, ao contrário da língua inglesa, parecem indicar o uso do processo fonológico de leitura, pois nas séries estudadas apenas uma pequena proporção das respostas denotou uma influência lexical, expressa por lexicalizações. Assim, partindo do processo sinalizado pela resposta, propomos classificar os erros de leitura em dois índices: um indicativo de tendência lexical e outro de tendência fonológica. A análise de erros proposta pode ser utilizada para averiguar a mudança de processos de leitura ao longo do desenvolvimento.
\end{abstract}

\section{Palavras-chave}

Leitura de palavras isoladas; Estratégias visual e fonológica de leitura; Respostas palavras reais; Lexicalização 


\section{Introdução1}

A análise dos erros cometidos na leitura de palavras pode ser esclarecedora quanto ao processo (ou rota) utilizado pelo leitor durante o reconhecimento de palavras. Isso ocorre porque uma leitura lexical — definida como o reconhecimento direto da ortografia, da pronúncia e do significado de uma palavra - pode produzir tipos de erros que são distintos daqueles causados por uma leitura fonológica - leitura baseada na construção da pronúncia e do significado da palavra a partir da aplicação de regras entre a grafia e o fonema. Desta forma, os erros gerados na leitura lexical ocorrem principalmente devido à semelhança visual entre o estímulo a ser lido (ou alvo) e outra palavra conhecida pelo leitor (seja em termos do compartilhamento de um grande número de letras na mesma posição — como as palavras: vasilha e vizinha - seja pelo compartilhamento de todas as letras na mesma posição, com exceção de uma - como bolo e bola $\underline{a}^{2}$ ). Podem também refletir uma interação entre a pronúncia produzida pela rota fonológica com a pronúncia da palavra arquivada no léxico fonológico (p. ex. mina e mima) ${ }^{3}$, assim como resultar da ativação de uma palavra dentro da categoria semântica a qual o estímulo alvo pertence. Podem, ainda, ter em comum com o alvo o mesmo radical, mas diferente flexão, gerando, portanto, os chamados erros semânticos (p. ex., ler "férias" por hotel) ou erros de derivação ("fome" por faminto), respectivamente.

Tomando-se as estruturas que compõem a rota lexical, podemos traçar a origem de cada um desses erros. Assim, de acordo com Seymour (1986), pressupõe-se que as respostas incorretas que geram uma palavra real são freqüentemente o produto da recuperação da pronúncia dessa palavra no léxico fonológico que pode resultar de: (1) um erro de discriminação visual no léxico ortográfico, o que explica a origem das respostas que se assemelham de forma visual com o alvo; (2) uma semelhança entre a pronúncia de duas palavras, uma gerada pela rota fonológica e a outra arquivada no léxico fonológico, o que explica a origem das respostas que se assemelham de forma fonológica com o alvo e (3) um erro de ativação do correto significado de palavras pertencentes a uma mesma categoria semântica ou da correta flexão de uma palavra, que, por sua vez, explica a origem das respostas que se relacionam ao alvo por semelhança semântica ou por derivação. 
Nos erros de discriminação visual do tipo vasilha/vizinha e bolo/bola, cuja origem acredita-se situar no léxico ortográfico, em ambos os casos estamos diante de erros que são genericamente chamados de lexicalização e que constituem respostas provocadas pela substituição da palavra (ou nãopalavra ${ }^{4}$ ) a ser lida por outra palavra existente na língua, que seja estruturalmente semelhante a ela em termos visuais. Assim, são tomados como indicadores do uso do processo lexical. Erros do tipo do primeiro par são chamados de confusão visual (p. ex., liberty lida 'library') ou de semelhança visual (p. ex., exceto lida como 'exército' ou 'extenso') por Seymour (1986) e Pinheiro (1989), respectivamente, por refletirem uma aproximação visual entre o alvo e a resposta. Já os erros semelhantes ao segundo par ocorrem em função do que é conhecido na literatura como efeito de vizinhança.

Segundo Coltheart, Davelaar, Jonasson e Besner (1977), duas palavras são vizinhas ortográficas quando elas compartilham exatamente o mesmo número de letras e na mesma posição, com exceção de uma. Assim 'vaca' e 'fada' são vizinhas ortográficas de faca, mas não de 'cara'. O número de palavras que pode ser criado tomando como referência essa definição é chamado de medida "N" (de neighbourhood, vizinhança em inglês) e se refere ao número de vizinhos da palavra-alvo.

A análise dos erros que geram palavras reais em resposta a um estímulo pode ser uma ferramenta útil na avaliação do efeito de vizinhança na leitura, sendo um método de investigação qualitativa desse fenômeno, assim como de outros erros causados por proximidade visual com a palavra alvo que não se enquadram na categoria de palavras vizinhas, como os erros de confusão visual ou de semelhança visual.

Em função da distinção entre os erros que ocorrem tanto por aproximação visual entre o alvo e a resposta quanto em função do efeito de vizinhança, o termo "respostas palavras reais" tem sido utilizado por Pinheiro (em todas as suas publicações) no lugar de lexicalização, pois, como será demonstrado, em uma ortografia mais regular do que a da língua inglesa, em que o efeito de vizinhança foi originalmente estudado, as respostas palavras reais podem incluir, além dos erros que denotam a influência de processos lexicais no reconhecimento de palavras (seja por ativação de palavras vizinhas ou de palavras com proximidade visual com o estímulo alvo), 
respostas que, ao contrário, sinalizam a utilização do processo fonológico. De fato, Pinheiro (1989), em um estudo sobre o desenvolvimento da leitura em uma amostra de crianças da $1^{\underline{a}}$ à $4^{\underline{a}}$ série, mostrou que, na nossa ortografia, os erros indicativos de processos fonológicos representaram altas porcentagens na leitura das crianças em todos os níveis escolares. Mostrou também que as baixas porcentagens de erros indicativos de uma influência lexical apresentaram um aumento significativo das séries iniciais às finais, 0 que foi interpretado como um sinal de utilização do processo lexical com o avanço no domínio da leitura.

O uso do processo lexical permite o reconhecimento rápido e preciso apenas da informação arquivada no léxico, ou seja, palavras de todos os tipos (p. ex., palavras de alta e baixa freqüência de ocorrência, regulares e irregulares, curtas e longas). O mesmo não acontece quando a leitura é feita pelo processo fonológico que, embora possa reconhecer tanto as palavras arquivadas no léxico quanto os estímulos não arquivadas nesse sistema (palavras desconhecidas e não-palavras), pode causar erros na pronúncia de palavras irregulares para a leitura. Estas, por definição e ao contrário das palavras regulares, apresentam relações grafema-fonema arbitrárias, podendo, portanto, não ser lidas corretamente por meio do uso das regras que norteiam essas relações, gerando, assim, os chamados erros de regularização (substituição de uma pronúncia irregular pela pronúncia mais freqüente de um determinado grafema, como, em nossa língua, ler $0<x>$ intervocálico como [j] $]^{5}$ em palavras cuja pronúncia correta é [ks], [s] ou [z]) e de troca de qualidade da vogal (leitura incorreta das vogais $<$ e $>$ e do $<0>$ que, na sílaba tônica e em posição paroxítona, apresenta pronúncia arbitrária (semi)aberta ou (semi)fechada). Assim, uma leitura mais rápida e mais correta de palavras regulares em comparação às palavras irregulares é conhecida como efeito de regularidade. Esse efeito é esperado quando leitores iniciantes lêem palavras de baixa freqüência de ocorrência (já que as palavras de alta freqüência tendem a ser lidas pela rota lexical, mesmo por iniciantes). Assim, o efeito de regularidade é tomado como um índice de leitura pela rota fonológica.

Adicionalmente aos erros de regularização e de troca de qualidade da vogal, todos os tipos de estímulos processados pela via fonológica podem apresentar erros na conversão grafema-fonema que, por natureza, são 
estruturalmente relacionados com os seus alvos, mas que contêm pequenas imprecisões na identificação de letras (causando trocas, acréscimo ou apagamento de letras, de agrupamento de letras ou de sílabas) e no seu posicionamento. Todos esses erros têm por característica a produção de respostas cuja pronúncia, na maioria dos casos, não se assemelha à pronúncia de uma palavra real (p. ex., a palavra boxe lida como 'boche', canela lida como 'camela'). Daí receberem na literatura a denominação de "neologismos" ou "respostas não-palavras6". Conseqüentemente, o acesso ao significado das palavras lidas incorretamente, principalmente as irregulares, pode ficar comprometido quando processadas pela via fonológica.

Tendo em vista que os erros cometidos na leitura podem fornecer indícios sobre os processos de leitura utilizados, e que a terminologia usada para indicar a causa do erro que gera uma palavra real (se por influência lexical ou não) ainda não foi claramente estabelecida ${ }^{7}$, o objetivo geral deste trabalho é, com base na freqüência dos tipos de erros na categoria "respostas palavras reais" e na categoria "respostas não-palavras", propor uma terminologia mais simples para ambos os tipos de erros, tomando como referência o processo que ele sinaliza mais do que o fato do erro gerar uma palavra real ou não. Como objetivo específico, propomos investigar a natureza dos erros de respostas de substituição de uma palavra real por outra palavra real, de forma a avaliar quando esses erros são lexicalizações, indicadores de uso de processo lexical, e quando são indicadores de uso de processo fonológico.

Com isso, esperamos confirmar dois pontos importantes sobre 0 processo de aquisição da leitura por nossas crianças. O primeiro é que, no português do Brasil, os erros de leitura dos iniciantes apontam para o uso de uma estratégia predominantemente fonológica (p. ex., Morais, 1986), mas com tendência a declinar das séries iniciais em direção às séries mais avançadas do Ensino Fundamental, mostrando assim a transição da leitura baseada em processo fonológico para a leitura lexical (p. ex., Pinheiro, 1994, 1995). O segundo é que, também em nossa língua, os erros de substituição de uma palavra real por outra palavra também real, mais do que uma lexicalização, é um sinal de leitura fonológica (Pinheiro, 1989). 


\section{Método}

\subsection{Amostra}

A amostra foi formada por 53 crianças da $1^{\text {a }}$ à $3^{\text {a }}$ série do Ensino Fundamental de uma escola da rede particular de Belo Horizonte (Minas Gerais, Brasil) e com desenvolvimento normal na habilidade de leitura. $O$ número de crianças em cada série foi de 21,18 e 14 na 1ํaㄹ $2^{\underline{a}}$ e $3^{\underline{a}}$ série, respectivamente.

\subsection{Instrumento}

Como instrumento utilizou-se o banco de itens construído por Pinheiro $(2004)^{8}$. Esse banco é formado por uma lista de 323 palavras, que variam em 4-8 letras e em categorias de regularidade quanto à relação grafema-fonema - palavras regulares $(R)$ e irregulares $(I R)$ - e que apresentam em comum a característica de ocorrerem em baixa freqüência de ocorrência no vocabulário exposto de forma escrita a crianças da $1^{\underline{a}}$ à $4^{\underline{a}}$ série do Ensino Fundamental, segundo a contagem de freqüência de ocorrência de Pinheiro $(1996)^{9}$. Para facilidade de aplicação e para evitar cansaço nas crianças, a referida lista foi dividida em duas partes, a Lista 1 e a Lista 2, contendo, respectivamente, 162 e 161 palavras. Ambas as Listas 1 e 2 foram inseridas em dois microcomputadores portáteis que, por meio de um programa específico para o estudo, apresentaram as palavras de cada lista no centro de sua tela. A leitura em voz alta das palavras pelas crianças e o tempo de reação para cada palavra foram automaticamente gravados durante o teste pelo próprio computador. Os erros foram marcados pelos aplicadores, que apertavam uma tecla específica, após cada ocorrência.

\subsection{Procedimento}

O teste, que consistiu na administração das Listas 1 e 2 às crianças, foi aplicado por bolsistas de IC do Curso de Psicologia/UFMG no final de 2001. Cada criança - testada individualmente - leu, em dois momentos, as palavras das duas listas, cuja ordem de apresentação era randomizada pelo próprio computador, mediante a seguinte instrução (dada antes da primeira sessão de testagem): "Agora nós vamos fazer uma atividade de leitura. Olhe bem para o centro da tela do computador. Nesta tela irão aparecer várias 
palavras, uma de cada vez, que você deve ler o mais rápido que puder e procurando não errar. Se você não souber ler, pode dizer que não sabe, mas o importante é que você tente ler. Podemos começar?". Na primeira sessão, havia um treinamento com uma lista de 10 palavras. A seguir, introduzia-se a primeira lista experimental, escolhida aleatoriamente. Na segunda sessão, que geralmente ocorria em um intervalo de três dias, era apresentada a outra lista. Cada lista possuía três pausas.

\subsection{A Classificação das palavras em níveis de regularidade}

As palavras do instrumento utilizado nesse estudo foram classificadas do ponto de vista da leitura em duas categorias: (1) palavras regulares $(R)$ : palavras formadas por grafemas que sempre representam o mesmo fonema (p. ex., lata ou cama) e palavras contendo correspondência grafema-fonema regida por regras que são dependentes de contexto (p. ex., o <r> e o <s> em contexto intervocálico, como nas palavras vara e casa); (2) palavras irregulares (IR): palavras contendo pelo menos uma correspondência grafema-fonema irregular como, por exemplo, o grafema $<x>$ entre vogais (nesse contexto, o <x> pode valer []], [z], [s], ou [ks] como em vexame, exame, trouxe e táxi, respectivamente) e os vocálicos $<0>$ e $<$ e $>$ em posição paroxítona (p. ex., cedo, seca, nono, copo) cuja pronúncia, (semi)aberta ou semifechada, é determinada lexicalmente.

\subsection{Definições de respostas palavras reais e de respostas não-} palavras e critérios de inclusão de respostas nessas categorias

\subsubsection{Respostas palavras reais}

Nas respostas palavras reais (aqui denominadas respostas-PRs), 0 erro consiste em produzir, em resposta ao estímulo a ser lido, uma resposta que se relaciona ao estímulo alvo em termos de semelhança ortográfica ( $p$. ex., ler 'onça' ao invés de ouça) ou de pronúncia (p. ex., ler 'menina' ao invés de mina) ou em termos de significado ou derivação.

Neste estudo, todas as respostas que geraram palavras reais foram classificadas como respostas-PRs, mesmo que a palavra gerada fosse bastante incomum para ser conhecida por uma criança (p. ex., ler viúva como 'vulva'), ou mesmo se ela pudesse ter sido causada por outro(s) erro(s) cuja(s) 
pronúncia(s) gera(m) uma palavra real acidentalmente, ao invés de por meio do processo lexical propriamente dito (p. ex., ler caro como 'carro', podendo haver, aqui, um erro contextual mais do que um erro indicativo de processamento lexical).

\subsubsection{Respostas não-palavras}

As respostas não-palavras (aqui denominadas respostas-NPs indicam o uso do processo fonológico na leitura e são classificadas nas seguintes categorias: 1) leitura silabada explícita (LSE) — quando se lê decodificando sílaba a sílaba, ou mesmo letra por letra, inserindo pausas entre as unidades do estímulo (p. ex., ler o estímulo saudade como 'sa...u...da...de'); 2) tradução grafema/fonema (TGF) - troca, acréscimo ou apagamento de letra, grupo de letras ou sílabas durante a pronúncia (p. ex., ler afeto como 'alfeto'); 3) troca de acentuação tônica (TAT) - quando a tonicidade da palavra é alterada ( $p$. ex., ler sarjeta como 'sarjetá'); 4) desconsideração de regras contextuais (DRC) - quando se erra a pronúncia de uma palavra em função da violação de uma regra contextual (p. ex., ler marido como 'marrido'); 5) Troca de qualidade de vogal (TQV) - quando se lê uma vogal (semi)aberta (<e> ou < > em sílaba tônica, cuja pronúncia é irregular) por uma semifechada e viceversa (p. ex., ler cedo como 'cédo'); 6) Regularização (REG) — a leitura incorreta do $<x>$ intervocálico (p. ex., ler fixo como 'ficho').

Os quatro primeiros tipos de erros podem ocorrer tanto na categoria regular quanto na irregular, inclusive aqueles gerados por desconsideração de regras, pois em ambas as categorias existem palavras que apresentam pronúncia regida por alguma regra contextual, como a palavra caro, na categoria regular, ou a palavra acesso, na categoria irregular, que, além do vocábulo <e> em sílaba tônica e em posição paroxítona, apresenta o grafema <S> em posição intervocálica. Já os dois últimos tipos, ocorrem sempre nas palavras irregulares com as palavras que apresentam os grafemas $<\mathrm{e}>\mathrm{e}<0>$ em sílaba tônica e o grafema $<x>$ intervocálico, podendo gerar erros de troca de qualidade de vogal e de regularização, respectivamente.

Existem, ainda, duas possibilidades de erros. As respostas de recusa (Seymour, 1986, Pinheiro, 1994), também conhecidas como não-respostas (Salles, 2005) ou ainda como ausência de respostas (Lecours, Parente, 
Teixeira e Silveira, 1997), em que o participante não consegue ler o estímulo apresentado, e a nomeação de letras (Salles, 2005), tipo de erro em que o participante soletra a palavra, mas não extrai som da mesma. Ambos os tipos de erros não apareceram na amostra do presente estudo, nem mesmo na leitura das crianças da $1^{\text {a }}$ série, e não se enquadram em nenhuma das duas categorias de respostas supracitadas, ou seja, de respostas-PRs ou de respostas-NPs.

Dentre as classificações de erros para as crianças brasileiras em fase de desenvolvimento da habilidade de leitura, a que mais se aproxima da nossa classificação é a de Salles (2005), que trabalhou com uma amostra de crianças de $2^{a}$ série do Ensino Fundamental. Salles (2005) considerou tanto com a leitura de palavras reais quanto com a de não-palavras e descreveu dez categorias de erros, seis delas comuns à leitura de ambos os tipos de estímulos: 1) os neologismos (quando a resposta gera uma não-palavra na leitura de palavras reais, ou uma não-palavra diferente do estímulo-alvo na leitura de não-palavras); 2) o desconhecimento de regras contextuais (classificação idêntica à que nomeamos desconsideração de regras contextuais ${ }^{10}$ ); 3) desconhecimento de regras de acentuação (referente à troca de acentuação tônica em nosso trabalho); 4) a substituição de fonemas surdos e sonoros; 5) as não-respostas e 6) a nomeação de letras, que foram anteriormente especificadas. Para as palavras reais especificamente, a autora distingue os erros de 7) regularização - substituição da correspondência grafema-fonema irregular de uma palavra por outra mais freqüente - e as 8) paralexias verbais e 9) verbais formais (que ocorrem quando uma palavra real é lida no lugar do estímulo, sendo que a resposta respectivamente não mantém semelhança nem semântica nem estrutural com o estímulo alvo, ou apenas mantém uma semelhança estrutural com este último). A décima categoria é a de lexicalização, que a autora utiliza apenas quando respostasPRs são dadas para a leitura de não-palavras.

Fazendo um paralelo entre essa classificação e a por nós proposta, primeiramente, acreditamos que a categoria "neologismos" é um tanto redundante, pois a maioria das respostas ocasionadas por outros tipos de erros (como regularização ou a troca de acentuação tônica) gera uma resposta não-palavra. Além disso, Salles (2005) classifica como paralexias formais verbais respostas tais como casa lida como ['kase] em que a palavra 
real gerada (nesse caso, 'cassa' do verbo caçar ou o substantivo 'caça') pode ter ocorrido tanto como resultado da violação de regras contextuais quanto como resultado de uma influência lexical ${ }^{11}$. Por fim, de acordo com a nossa classificação, os erros de substituição de fonemas surdos por sonoros e viceversa estão incluídos na categoria ampla "tradução grafema-fonema", já que essa categoria de erros inclui todas as possibilidades de troca, adição, apagamento de letras/sílabas, sendo o levantamento desses tipos de erros um desdobramento da categoria sob consideração.

\section{Resultados e discussão}

Em uma análise de erros, geralmente, considera-se apenas um erro por palavra, independentemente da resposta conter mais de um erro, como por exemplo, a palavra costa lida como 'gasta' em que há duas trocas de letras em resposta a um mesmo estímulo. Essa é uma contagem quantitativa de erros. Já em uma análise qualitativa, contam-se e classificam-se todos os erros ocorridos, o que pode variar de um a mais de um erro por palavra. Assim, os resultados aqui relatados tomaram como base a quantidade e qualidade dos erros cometidos na leitura das 323 palavras da lista de Pinheiro (2004). No que se refere à quantidade ${ }^{12}$, como uma ilustração da proporção dos erros feitos pela amostra, as crianças da primeira série apresentaram uma média de $7 \%$ de erros. Essa média de erros é equivalente à proporção de erros (7,5\%) encontrada por Pinheiro (1994) em uma amostra equivalente (tanto em número de sujeitos quanto em nível socioeconômico), que leu uma lista de 96 palavras. Em síntese, as crianças de todas as séries do presente estudo leram as palavras apresentadas com grande proficiência. Levando em conta o grande número de palavras que compõe a lista utilizada, o resultado obtido foi admirável.

Os erros produzidos pelas crianças em cada série foram o input para as análises que se seguem. Vale lembrar que o nosso foco aqui, adicionalmente aos objetivos já mencionados, é tentar resolver problemas teóricos relacionados à elucidação dos tipos de erros produzidos em uma tarefa de leitura em voz alta, com ênfase nas respostas-PRs, de forma a poder oferecer uma referência para orientar aqueles que se deparam com a tarefa de conduzir uma análise de erros. 


\subsection{Análise resultante da contagem quantitativa dos erros}

A contagem quantitativa consistiu de três tipos de levantamentos de erros para cada série. No primeiro, distinguiu-se o percentual dos erros que geraram palavras reais (as respostas-PRs) e o percentual de erros que geraram não-palavras (as respostas-NPs). No segundo, distinguiu-se o percentual de erros de respostas-PRs e de respostas-NPs em função da categoria de regularidade das palavras. O terceiro levantamento considerou apenas as respostas-PRs, calculando-se as porcentagens desse tipo de respostas em função do número de letras que compõem as palavras.

Tomando a porcentagem geral das respostas-PRs e das respostasNPs em função da série (com todas as categorias de regularidade juntas) encontramos que os erros do tipo respostas-NPs predominaram na amostra, mas as respostas-PRs apresentaram elevadas porcentagens em todas as séries $\left(25 \%, 27 \%\right.$ e $31 \%$, para a 1a., 2a. e 3a. série respectivamente) ${ }^{13}$, além de certa tendência de crescimento com o decorrer da escolarização.

A Tabela 1 mostra o percentual de erros de respostas-PRs e de respostas-NPs para cada série, em função da categoria de regularidade das palavras. Podemos observar que as respostas-PRs apresentaram uma proporção expressivamente maior na categoria regular do que na irregular. $\mathrm{Na}$ tentativa de entender esse padrão de resposta, levantamos os percentuais de erros cometidos nas palavras regulares independentes de contexto e nas regidas por regras contextuais e constatamos que a maior proporção das respostas-PRs entre as palavras regulares em relação às irregulares deveuse aos erros cometidos nas palavras regidas por regras contextuais, sendo a proporção de respostas-PRs nas palavras desta categoria na ordem de $85 \%$, $65 \%$ e $82 \%$ na $1^{a}$, $2^{\text {a }}$ e $3^{\text {a }}$ série, respectivamente ${ }^{14}$. 
Tabela 1 - Percentual de respostas palavras reais (PR) e de respostas não-palavras (NP) em função da categoria de regularidade das palavras para a leitura

\begin{tabular}{cccccc}
\hline Tipo de resposta/série & \multicolumn{4}{c}{ Categoria de regularidade para a leitura } \\
& \multicolumn{2}{c}{ R } & IR & \\
\hline & PR & NP & PR & NP \\
& $1^{\mathrm{a}}$ & 40 & 60 & 20 & 80 \\
$2^{\mathrm{a}}$ & 36 & 64 & 24 & 76 \\
$3^{\mathrm{a}}$ & 37 & 63 & 26 & 74 \\
\hline
\end{tabular}

$\mathrm{R}=$ palavras regulares; $\mathrm{IR}=$ palavras irregulares

O total de respostas-PRs em função do número de letras que compõe as palavras é apresentado na Tabela 2. Nas séries iniciais ( $1^{\underline{a}}$ e $2^{\underline{a}}$ séries), esse tipo de erro ocorreu em porcentagens bastante elevadas nas palavras de 4 e 5 letras, começando a declinar entre as palavras de 6 letras e, finalmente, diminuindo expressivamente entre as palavras de 8 letras. $\mathrm{Na} 3^{\underline{a}}$ série, a porcentagem de erros de respostas-PRs permaneceu mais ou menos constante, havendo um declínio maior nas palavras de 8 letras, sendo que, no geral, o declínio observado não foi tão expressivo quanto o que ocorreu nas demais séries. Como tentaremos explicar mais adiante, o padrão exibido pela $3^{\underline{a}}$ série refere-se à produção de uma maior proporção de lexicalizações pelas crianças dessa série em relação às séries iniciais.

Tabela 2 - Porcentagens de erros de respostas palavras reais (respostas-PRs) para cada série em função do número de letras que compõe as palavras

\begin{tabular}{cccccc}
\hline Série & \multicolumn{5}{c}{ Número de letras das palavras } \\
\hline & $\mathbf{4}$ & $\mathbf{5}$ & $\mathbf{6}$ & $\mathbf{7}$ & $\mathbf{8}$ \\
$1^{\mathrm{a}}$ & 29 & 38 & 26 & 14 & 7 \\
$2^{\mathrm{a}}$ & 31 & 42 & 19 & 25 & 12 \\
$3^{\mathrm{a}}$ & 38 & 32 & 22 & 31 & 19 \\
\hline
\end{tabular}


3.2. Análise resultante da contagem qualitativa dos erros com foco nas respostas-PRs

A análise qualitativa dos erros efetuada tanto para as respostas-PRs quanto para as respostas-NPs considerou todos os erros ocorridos em cada item, pois, como vimos, um mesmo item pode conter mais de um erro. No que se refere às respostas-PRs, é necessário esclarecer que toda e qualquer resposta que gerou uma palavra real foi enquadrada nesse tipo de erro na análise quantitativa. Quando a resposta-PR ocorreu em resposta a um erro de TGF, TAT, DRC ou TQV (ou mesmo como resultado da combinação de um ou mais desses erros), isso foi registrado na análise qualitativa. Desta forma, somente quando na análise qualitativa não são identificados erros que sinalizam leitura fonológica em uma resposta-PR é que podemos dizer que esse tipo de erro é gerado pelo uso de processamento lexical na leitura. Em outras palavras, as lexicalizações são identificadas por meio de um critério de exclusão que repousa no fato de a resposta não ter apresentado nenhum dos erros causados por falhas no processo fonológico que são levantados pela análise qualitativa. A Tabela 3 apresenta exemplos de erros que sinalizam uso de processo fonológico nas respostas categorizadas na análise quantitativa como respostas-PR.

Tabela 3 - Exemplos de erros de respostas palavras reais em que foram identificados erros que sinalizam uso de processo fonológico

\begin{tabular}{|c|c|c|}
\hline Estímulo & Análise quantitativa & Análise qualitativa \\
\hline bala & bola & TGF \\
\hline fera & ferra & DRC/TQV \\
\hline cota & gota & TGF/TQV \\
\hline xale & chalé & TAT \\
\hline
\end{tabular}

TGF = erro na tradução grafema-fonema; $\mathrm{DRC}=$ desconsideração de regra contextual; TQV = troca de qualidade da vogal; TAT $=$ troca de acentuação tônica

Conforme dito anteriormente, altos índices de erros que geram respostas-PRs podem indicar o uso de processamento lexical. Entretanto, uma análise detalhada dos tipos de erros que possivelmente geraram de 
maneira acidental uma resposta-PR, levantamento este feito na análise qualitativa, demonstrou que as respostas-PRs na realidade foram, em sua maioria, devidas a TGF, TQV e DRC mais do que a uma lexicalização — ou seja, podem não ter sido geradas em função do uso de processo lexical. Tomando, por exemplo, os erros TGF, constatamos que muitas respostas-PRs parecem ter resultado de uma simples troca de consoante/consoante (p. ex., ler 'sobra' por sogra) ou de uma troca de uma consoante acompanhada pela não consideração de uma regra contextual (p. ex., 'burra' para o alvo dura). A Tabela 4 apresenta, para cada série, os tipos de erros e as respectivas porcentagens que foram levantados pela análise qualitativa das respostasPRs ${ }^{15}$.

Tabela 4 - Porcentagens dos tipos de erros que sinalizam processo fonológico encontrados entre os erros que geraram respostas palavras reais nas diferentes categorias de regularidade e séries

\begin{tabular}{ccccc}
\hline $\begin{array}{c}\text { Categorias de } \\
\text { Regularidade }\end{array}$ & Tipo de erro & & Série & \\
& & $\mathbf{1}^{\text {a }}$ & $\mathbf{2}^{\mathbf{a}}$ & $\mathbf{3}^{\text {a }}$ \\
\hline $\mathrm{R}$ & LSE & 2 & 5 & - \\
& TGF & $\mathbf{5 9}$ & $\mathbf{6 0}$ & $\mathbf{6 8}$ \\
& TAT & 2 & 5 & - \\
& DRC & $\mathbf{2 0}$ & $\mathbf{2 8}$ & $\mathbf{3 2}$ \\
\hline $\mathrm{IR}$ & LSE & 1 & - & - \\
& TGF & $\mathbf{4 7}$ & $\mathbf{4 2}$ & $\mathbf{3 8}$ \\
& TAT & 1 & 4 & 4 \\
& DRC & $\mathbf{4 2}$ & $\mathbf{3 5}$ & $\mathbf{3 8}$ \\
& TQV & $\mathbf{5 5}$ & $\mathbf{4 4}$ & $\mathbf{6 2}$ \\
\hline
\end{tabular}

LSE = leitura silabada explícita; TGF = erro na tradução grafema-fonema; TAT = troca de acentuação tônica; $\mathrm{DRC}=$ desconsideração de regra contextual; TQV = troca de qualidade da vogal

Como se pode observar, na categoria regular existe uma predominância de erros por tradução grafema-fonema (TGF) nas três séries, sendo que os erros por desconsideração de regras contextuais também foram muito elevados. Houve uma tendência de acréscimo de ambos os tipos de 
erros com a escolarização. Já na categoria irregular, a predominância é dividida mais ou menos homogeneamente entre os erros de troca de qualidade da vogal (TQV), de tradução grafema-fonema e por desconsideração de regras contextuais, sendo que os dois últimos apresentam um padrão inverso ao longo das séries, ou seja, ocorreu uma diminuição desses erros das séries iniciais às finais e os erros TQV apresentaram um padrão em forma de $U$ com o decorrer da escolarização.

O indício de uso de processamento fonológico revelado na análise qualitativa das respostas-PRs, que acabamos de ilustrar, é reforçado quando analisamos a prevalência do total desse tipo de erro em função do número de letras que compõe as palavras (Tabela 2). Como demonstrado, nas séries iniciais, a proporção de respostas-PRs predominou nas palavras de 4 e 5 letras, mas, na $3^{\text {a }}$ série, permaneceu em proporções mais ou menos constantes em todos os comprimentos de palavras (exceto nas palavras de 8 letras). O curioso é que esse padrão de respostas-PRs exibido pelas crianças das séries iniciais é muito semelhante às expectativas sobre o efeito de regularidade encontrado na literatura, que também começa a declinar entre as palavras de maior comprimento já que, como nos mostram Rastle e Coltheart (1999), o tamanho da desvantagem incorrida pela palavra irregular declina em função da posição da correspondência grafema-fonema irregular nas palavras. Ou seja, começando da esquerda-para-a-direita, quanto mais cedo se situar a correspondência irregular maior é o efeito de regularidade (assim as palavras curtas são mais afetadas pela irregularidade do que palavras longas). Isso ocorre porque, de acordo com o modelo de dupla rota em cascata, como a leitura pela rota fonológica ocorre por meio de processamento serial, os itens de menor comprimento são lidos por essa rota mais rapidamente do que os itens maiores. Além disso, como a leitura é feita simultaneamente pelas rotas lexical e fonológica, quando a palavra a ser lida é de baixa freqüência - como é o caso do presente estudo - a pronúncia gerada pela rota fonológica para os itens menores pode chegar mais rapidamente ou ao mesmo tempo no nível de fonema do que a leitura pela rota lexical, pois, neste caso, a consulta ao léxico se efetua com uma menor rapidez em relação às palavras de alta freqüência. Isso resulta em um efeito de regularidade em termos de erros - pois aumenta a probabilidade de que a pronúncia incorretamente gerada seja escolhida — e/ou de tempo de reação 
- pois a pronúncia discordante gerada pelas duas rotas exige uma nova consulta ao léxico para uma verificação.

Assim, a semelhança de padrões entre as respostas-PRs e o efeito de regularidade em função do comprimento de palavras reafirma a hipótese de que a produção de respostas-PRs, contrariamente do que se esperaria, parece resultar de um processamento fonológico. Essa hipótese ganha mais força quando comparamos o padrão de respostas-PRs das crianças das séries iniciais com os da $3^{\underline{a}}$ série, também em função do número de letras contido nas palavras. Nessa série, por as crianças já estarem lendo de forma mais lexical, as suas respostas-PRs mudam de natureza. Passam a ser baseadas na semelhança ortográfica (p. ex., 'freqüência' para a palavra alvo freguesa) ou fonológica (p. ex., 'menina' para mina) revelando, portanto, uma influência lexical (e não mais fonológica). Por isso, não são afetadas pelo comprimento das palavras e podem ser consideradas respostas-PRs genuínas, que são as chamadas de lexicalizações.

Com a finalidade de entender o padrão das respostas-PRs genuínas, que passaremos a chamar de lexicalização ${ }^{16}$, levantou-se as porcentagens desse tipo de resposta para todas as séries, como podemos ver na Tabela 5. Em comparação com as respostas-PRs que ocorreram como resultado de processamento fonológico, as porcentagens de lexicalização (8\%, 7\% e 18\% para a $1^{\underline{a}}, 2^{\underline{a}}$ e $3^{\underline{a}}$ série, respectivamente), no geral, foram bem menores. Entretanto, o número reduzido desse tipo resposta entre as palavras de menor comprimento em relação às palavras de maior comprimento ilustra que o processamento fonológico é mais influente entre as palavras menores. Além disso, confirmando os achados de Pinheiro (1989), observou-se um aumento da proporção de respostas-PRs consideradas genuínas das séries iniciais para as finais, o que sinaliza a transição da leitura fonológica para a leitura lexical ${ }^{17}$. Outro indício dessa transição foi o aumento das lexicalizações das séries iniciais à $3^{\underline{a}}$ série, a partir das palavras com sete letras. 
Tabela 5 - Porcentagens de lexicalizações cometidas em cada série em função do número de letras que compõe as palavras e no total

\begin{tabular}{|c|c|c|c|c|c|c|}
\hline Série & 4 letras & 5 letras & 6 letras & 7 letras & 8 letras & Total \\
\hline $1^{\mathrm{a}}$ & - & 6 & 14 & 29 & - & 8 \\
\hline $2^{\mathrm{a}}$ & 5 & - & - & 21 & 20 & 7 \\
\hline $3^{\mathrm{a}}$ & - & - & 14 & 47 & 100 & 18 \\
\hline
\end{tabular}

\section{Conclusões}

Considerando que uma análise criteriosa dos erros produzidos nas tarefas de reconhecimento de palavras não tem recebido uma atenção especial na literatura e que nos poucos relatos sobre o tema não se nota uma consistência nas classificações efetuadas e nem na terminologia utilizada para se referir aos diferentes tipos de erros, a nossa proposta foi, com base em um detalhado estudo sobre a natureza dos tipos de erros produzidos em uma tarefa de leitura em voz alta de palavras reais, a de propor uma classificação simplificada de erros tomando como referência o tipo de processo que ele traduz. A expectativa é que o que se descobriu possa ser generalizado para os erros cometidos em uma tarefa de leitura de não-palavras, que é um dos meios de se avaliar o processo de decodificação fonológica.

Como esperado, conseguimos confirmar que os erros de leitura de nossos aprendizes apontam para 0 uso de uma estratégia predominantemente fonológica, mas com a influência da utilização dessa estratégia apresentando uma tendência a declinar com o avanço da escolarização, mostrando assim a transição da leitura baseada em processo fonológico para a leitura lexical. A utilização inicial do processo fonológico no reconhecimento de palavras mostrou ter implicações específicas para os erros de substituição de uma palavra real por outra palavra também real que, ao invés de ser um indicativo de leitura lexical, como se nota em uma ortografia mais irregular como a do inglês, é, na nossa ortografia, mais um sinal de leitura fonológica do que lexical, confirmando assim que uma proporção das respostas-PRs ocorre acidentalmente ao se utilizar o processo de decodificação, o que é outro ponto específico sobre o estudo de reconhecimento de palavras no nosso idioma. Disso decorre que a porcentagem total desse tipo de resposta deve ser interpretada com cautela; isto é, não inteiramente como um indício de leitura lexical. 
Isso nos leva a afirmar que a análise utilizada para todos os tipos de erros, da forma aqui demonstrada, é uma forma eficaz de se conhecer a origem fonológica ou lexical dos erros. Sentimos, então, que estamos agora na posição de oferecer as recomendações que se seguem para a condução de uma análise de erros na tarefa sob consideração. Sendo a condução da análise de erros aqui proposta um procedimento simples para a identificação do processo de leitura utilizado pela criança, ela certamente será de utilidade tanto para o psicólogo clínico que realiza o diagnóstico dos problemas de leitura, quanto para a professora que seleciona as estratégias de ensino mais adequadas de acordo com o nível de aprendizagem da criança.

Diante dos erros produzidos em uma tarefa de leitura em voz alta, o primeiro procedimento deve ser o levantamento da porcentagem de respostas que geram palavras reais (independentemente da natureza lexical ou fonológica dessas respostas), por um lado, e, por outro, o levantamento da porcentagem das respostas que não geram uma palavra real. A seguir, para cada item de cada categoria de erros, deve-se proceder a uma análise qualitativa que consiste na identificação do(s) tipo(s) de erro(s). Nas respostas-PRs, essa análise esclarecerá a natureza das respostas e, nas respostas-NPs, permitirá uma avaliação do estado de aquisição do processo fonológico.

Considerando as respostas-PRs, um dos focos de nosso trabalho, o ponto mais importante será a identificação dos índices de leitura lexical. Assim, deve-se levantar a porcentagem de erros ocorridos devido à semelhança visual, fonológica e semântica ou por derivação que, por sua vez, denotam, respectivamente, o processamento impreciso no léxico ortográfico, a influência de processamento lexical na produção de uma resposta pela rota fonológica e a imprecisão na recuperação da informação no sistema semântico.

Para os erros ocorridos em função de falhas na discriminação visual em decorrência de semelhança visual entre alvo e resposta, adotaremos a terminologia lexicalização independentemente de serem esses erros causados por confusão visual ou pelo efeito de vizinhança.

Uma vez apurada a proporção de erros que sinalizam a influência de processamento lexical (incluindo nela as lexicalizações, os erros por semelhança fonológica e erros semânticos e de derivação), o restante das 
respostas que geraram palavras reais deve, juntamente com as respostasNPs, ser considerado como sinal de influência fonológica. Assim, terminamos a nossa análise com apenas dois índices, um indicativo de tendência lexical e o outro indicativo de tendência fonológica na produção de erros. Já que esse levantamento deve resultar de uma contagem quantitativa (pois a contagem qualitativa será feita apenas para a avaliação da natureza dos erros), o seu total deve ser 100 .

No entanto, é importante enfatizar que, no caso exemplificado (assim como em outros casos semelhantes), a forma mais inequívoca de avaliar o tipo de processo utilizado para ler um estímulo é por meio da medida de tempo de reação. Como a leitura pela rota lexical é mais rápida do que a leitura pelo processo fonológico, o tempo de reação da resposta incorreta deve ser observado. Assim, a expectativa é que as respostas-PRs, que são geradas como resultado de uma influência lexical, mostrem um menor tempo de processamento do que as respostas-PRs que são geradas acidentalmente em decorrência de uma decodificação fonológica imprecisa.

Finalmente, caso queiramos fazer previsões a respeito da mudança de estratégia de leitura ao longo do desenvolvimento, sugere-se a utilização de uma lista em que seja feito o controle sobre o nível de freqüência de ocorrência, a regularidade grafema-fonema e número de letras das palavras. $\mathrm{O}$ achado de que uma análise de erros da forma que aqui foi conduzida pode lançar hipóteses sobre a mudança de processos ao longo do desenvolvimento representa, sem dúvidas, um avanço nos estudos sobre reconhecimento de palavras, principalmente considerando que no Brasil muito raramente se usa a medida de tempo de reação como forma complementar a análise de erros para a avaliação dos processos de leitura.

\section{Notas}

1 Agradecemos ao apoio financeiro da Fapemig e do CNPq.

2 Voltaremos a esse ponto mais adiante no texto.

3 Em português, é muito difícil fazer uma distinção entre as respostas geradas por semelhança ortográfica com o estímulo-alvo e as respostas geradas por semelhança fonológica. No caso do par mina e mima, há uma semelhança tanto fonológica quanto ortográfica. Existe também a possibilidade desse erro ter ocorrido como resultado de uma simples troca de letra $(\mathrm{n} / \mathrm{m})$, sendo, portanto, um erro de tradução gafema-fonema mais do que um indício de leitura lexical. 
4 Não-palavras são seqüências de letras formadas de acordo com as estruturas ortográficas possíveis em uma língua, mas não associadas a nenhum significado. São estímulos utilizados para testar o processo de decodificação fonológica, que é o processo central da rota fonológica, e os efeitos decorrentes da interação entre essa rota e a lexical. Assim, a substituição de uma não-palavra (p. ex., dacão) por uma palavra real semelhante a ela (p. ex., facão) é tomada como um indício de uma influência lexical na leitura desse estímulo, que deveria, em princípio, ser processado pela rota fonológica. Coltheart et al. (2001) se referem ao fenômeno de ao ler uma não-palavra dar a ela a pronúncia de uma palavra real que tenha com ela semelhança ortográfica ou fonológica como captura lexical (do inglês "lexical capture").

5 No Alfabeto Fonético Internacional o símbolo []] corresponde ao dígrafo <ch>.

6 O primeiro termo tem sido mais freqüentemente utilizado na área de estudos sobre dislexia adquirida e o segundo tem sido utilizado por Seymour em grande parte de suas publicações sobre o estudo do desenvolvimento normal da leitura e sobre a dislexia do desenvolvimento. Portanto, doravante utilizaremos o termo "respostas não-palavras" para designar as respostas que não se assemelham a palavras reais e que são emitidas por crianças normais ou com problemas na aquisição da habilidade de leitura.

7 Tanto na literatura estrangeira quanto na brasileira, os relatos sobre a classificação dos erros de leitura são imprecisos e incompletos.

8 Esse corpo de itens foi recentemente publicado em Sim-Sim, Inês \& Viana, Fernanda L. (2007).

9 A contagem de freqüência de ocorrência de palavras de Pinheiro (1996) levou em consideração todas as palavras escritas em livros didáticos utilizados em escolas de $1^{\underline{a}}$ à $4^{\mathrm{a}}$ série do Ensino Fundamental de vários estados brasileiros.

10 Acreditamos que o termo "desconsideração" é mais adequado do que o termo "desconhecimento" porque o fato de uma criança errar a pronúncia de um grafema governado por regras contextuais não implica que ela cometerá o mesmo erro em outras palavras, ou seja, que ela desconheça completamente a regra. Há a possibilidade que ela tenha apenas deixado de aplicar uma regra já conhecida, o que pode ser demonstrado pela presença desse tipo de erro em apenas algumas palavras (Pinheiro, 2005).

11 Considerando esse impasse sobre como classificar as resposta-PRs, cuja origem lexical ou fonológica é ambígua, uma classificação de erros do tipo da que estamos propondo pode ser esclarecedora. Isto é, em um primeiro momento, separamos as respostas que geram palavras reais das respostas não-palavras, e, posteriormente, procedemos a uma análise qualitativa, a fim de se identificar os tipos de erros cometidos em ambos os tipos de respostas. Assim, tomando a situação em que a palavra casa é lida com o intervocálico <s> pronunciado como [s], em uma análise individual, se a criança em questão ao ler outras palavras (ou não-palavras) incorrer no mesmo tipo de erro, ou seja, evidenciar pouco domínio da pronúncia do <s> intervocálico e ao mesmo tempo apresentar um baixo índice de respostas palavras reais que denote 0 uso do processo lexical, podemos, com grande chance de acerto, concluir que a troca de casa por ['kase] é mais um sinal de leitura fonológica do que lexical. 
12 No que se refere à qualidade, não foram conduzidas no trabalho de Pinheiro (1994) análises como as que serão aqui apresentadas, as quais especificassem os tipos de erros das crianças, não sendo possível, portanto, uma comparação.

13 Devemos notar que as porcentagens de respostas-PRs apresentadas neste estudo são bem mais elevadas do que as do estudo de Salles (2005), que encontrou uma média de 0,65 erros de paralexia verbal formal e de 0,08 erros de paralexia verbal em sua amostra de crianças de $2^{\underline{a}}$ série. No entanto, talvez esse resultado se deva ao método utilizado para a apresentação dos estímulos pela autora, em que as palavras e não-palavras foram apresentadas em uma mesma lista, ao invés de em listas separadas, o que talvez tenha forçado a adoção de uma estratégia fonológica pelos participantes, reduzindo os erros do tipo respostas-PRs. Para uma discussão sobre os efeitos estratégicos na leitura, ver Coltheart et al. (2001), que apresentaram evidências de que os leitores podem alterar a força de um canal de comunicação do seu sistema de leitura em resposta a instrução da tarefa.

14 É importante ressaltar que a despeito desse resultado, uma comparação entre o número geral de erros entre os dois tipos de regularidade de palavra não gerou uma diferença significativa, daí a inclusão das duas classes de estímulo em uma mesma categoria.

15 Os valores mostrados nessa tabela foram obtidos dividindo-se o número de erros obtidos na análise qualitativa da resposta-PR sob consideração pelo total de erros na categoria de respostas-PRs (em cada série separadamente). É importante ressaltar, conforme demonstrado no exemplo acima, que uma mesma palavra pode gerar mais de um erro na análise qualitativa, portanto, a soma dos erros não dará 100.

16 Preferimos esse termo, já que o termo captura lexical parece ser utilizado de forma mais limitada. Ou seja, quando o estímulo alvo é uma não-palavra.

17 De maneira semelhante ao que foi encontrado por Pinheiro (1989), não encontramos dentre essas respostas erros semânticos ou de derivação.

\section{Referências}

COLTHEART, Max; DAVELAAR, Eddy; JONASSON, Jon T. \& BESNER, Derek. (1997). Acess to the internal lexicon. In S. Dornie (Ed.) Attention and Performance, vol. I, no 1. Hillsdale, NJ: Erlebaum, pp. 535-555.

COLTHEART, Max; RASTLE, Kathleen; PERRY, Conrad; LANGDON, Robyn \& ZIEGLER, Johannes (2001). DRC: a dual route cascaded model of visual word recognition and reading aloud. Psychological Review, vol. 108, oㅜ 1, pp. 204-256.

LECOURS, André; PARENTE, Maria A. de M. P.; TEIXEIRA, Maria \& SILVEIRA, Adriana da (1997). Paralexias e paragrafias. In A. Lecours \& M. A. M. P. Parente (orgs.), Dislexia: Implicações do Sistema de Escrita do Português. Porto Alegre: Artes Médicas, pp. 107-122.

MORAIS, Artur G. (1986). O Emprego de Estratégias Visuais e Fonológicas na Leitura e Escrita em Português. Tese de doutorado não publicada. Recife: Universidade Federal de Pernambuco. 
PINHEIRO, Ângela M. V. (1989). Reading and Spelling Development in Brazilian Portuguese. Tese de doutorado não publicada. Universidade de Dundee, Escócia.

PINHEIRO, Ângela M. V. (1994). Leitura e Escrita: Uma Abordagem Cognitiva. São Paulo: Editorial Psy.

PINHEIRO, Ângela M. V. (1995). Reading and spelling development in Brazilian Portuguese. Reading \& Writing, special issue on Literacy Acquisition, Vol. 7, ํ1, pp. 111-138.

PINHEIRO, Ângela M. V. (1996). Contagem de Freqüência de Ocorrência e Análise Psicolingüística de Palavras Expostas a Crianças na Faixa Pré-escolar e Séries Iniciais do $1^{\circ} \mathrm{grau}$. São Paulo: Associação Brasileira de Dislexia.

PINHEIRO, Ângela M. V. (2004). Banco de palavras de baixa freqüência de ocorrência, para crianças brasileiras da $1^{\underline{a}}$ à $4^{\underline{a}}$ série do Ensino Fundamental, classificadas em termos de estrutura silábica, número de letras e regularidade para leitura e para escrita. Relatório técnico-científico de atividades da FAPEMIG (Ref.: DC/SOT 1202/2004). Belo Horizonte: Universidade Federal de Minas Gerais, Departamento de Psicologia.

PINHEIRO, Ângela M. V. (2005). Relatório parcial de atividades de pesquisa CNPq. Período: Agosto de 2003 a Fevereiro de 2004. Belo Horizonte: Universidade Federal de Minas Gerais, Departamento de Psicologia.

RASTLE, Kathleen \& COLTHEART, Max (1999). Serial and strategic effects in reading aloud. Journal of Experimental Psychology: Human Perception and Performance, vol. 25, no2, pp. 482-503.

SALLES, Jerusa F. (2005). Habilidades e Dificuldades de Leitura e de Escrita em Crianças de 2a Série: Abordagem Neuropsicológica Cognitiva. Tese de doutorado não publicada, Universidade Federal do Rio Grande do Sul, RS.

SIM-SIM, Inês \& VIANA, Fernanda L. (2007). Para a Avaliação do Desempenho de Leitura. Lisboa: Ministério da Educação/Gabinete de Estatística e Planeamnto da Educação. 


\section{WORD READING ALOUD TASK: AN ERROR ANALYSES PROPOSAL}

\section{Abstract}

In this study we investigated the strategies used by Brazilian children in a wordlist reading aloud task. Concentrating on the nature of the type of error that produces real words, we distinguished those kinds of responses that suggest the use of lexical processing (or a dictionary-look up strategy) from those that suggest the use of phonological processing (or a rule based strategy). We concluded that the "real word responses" for Brazilian Portuguese, differently from English, seem to indicate the use of phonological processing in reading, due to the fact that in all grades studied only a small proportion of the responses showed a lexical influence, indicated by lexicalizations. Thus, based on the processing indicated by the response we suggest a classification of reading errors according to these two types: one which points to a lexical tendency and the other to a phonological tendency. The proposed error analysis could be used in the evaluation of developmental changes in reading processes.

\section{Keywords}

Isolated word reading; Visual and phonological reading strategies; Real word responses; Lexicalization 
TAREA DE LECTURA DE PALABRAS AISLADAS: UNA PROPOSTA DE ANÁLISIS DE ERRORES

Resumen

El estudio investiga las estrategias utilizadas por niños brasileños en la lectura en voz alta de palabras aisladas. Tomando como foco la investigación de la naturaleza de los errores que generaron palabras reales, se han distinguido los tipos de respuestas que sugerían la utilización del proceso lexical (el reconocimiento automático de las palabras) de aquellas que sugerían el uso del proceso fonológico (o la construcción de la pronunciación de la palabra por el uso de procedimientos de conversión grafema-fonema). Se concluyó que las "respuestas palabras reales", en el portugués brasileño, al contrario de la lengua inglesa, parecen indicar el uso del proceso fonológico de lectura, pues en las series estudiadas sólo una pequeña proporción de las respuestas denotó una influencia lexical, expresa por lexicalizaciones. Así, partiendo del proceso señalado por la respuesta, proponemos clasificar los errores de lectura en dos índices: uno indicativo de tendencia lexical y otro de tendencia fonológica. El análisis de errores propuesto puede ser utilizado para verificar el cambio de procesos de lectura a lo largo del desarrollo.

Palabras-clave

Lectura de palabras aisladas; Estrategias visual y fonológica de lectura; respuestas palabras reales; Lexicalización

Recebido em Janeiro, 2008

Aceite para publicação em Junho, 2008

Toda a correspondência relativa a este artigo deve ser enviada para: Ângela Maria Vieira Pinheiro, Av. Antônio Carlos, 6.627, Belo Horizonte, Minas Gerais, Brasil. CEP 31270-901, Brasil. Tel: (31) 3409-5022 